\title{
Produção fermentativa de polissacarídeos extracelulares por bactérias
}

\section{Fermentative production of exocellular polysaccharides by bacteria}

\author{
Daniela Maria de Souza ${ }^{1 *}$; Crispin Humberto Garcia-Cruz ${ }^{2}$
}

Resumo

Os exopolissacarídeos, chamados de biopolímeros ou gomas hidrossolúveis, são produzidos por uma grande variedade de microrganismos e possuem propriedades físicas, estruturais e químicas bastante homogêneas, em relação aos derivados de algas e plantas. A produção é independente de condições climáticas, maior rapidez na obtenção do produto acabado e o espaço necessário é relativamente pequeno; esses biopolímeros, têm sido amplamente estudados nos últimos anos. Devido a ampla diversidade em estrutura e propriedades físicas, os polissacarídeos microbianos possuem muitas aplicações em industrias de alimentos, farmacêutica, petrolífera, cosmética, têxtil, de tintas, produtos agrícolas entre outras. Algumas dessas aplicações, dependendo de sua estrutura química, incluem seu uso como emulsificantes, estabilizantes, ligantes, agentes gelificantes, coagulantes, lubrificantes, formadores de filme, espessantes e agentes suspensores. Os parâmetros que mais influenciam o processo de biossíntese de exopolissacarídeos são o microrganismo produtor, a composição do meio de cultivo, o pH e a temperatura de incubação. A produção de exopolissacarídeos pode ser realizada com espécies de bactérias Gram-negativas e Gram-positivas, algumas microalgas e muitos fungos. Este trabalho discute a influência destes parâmetros durante o processo de produção e biossíntese de exopolissacarídeos produzidos por bactérias.

Palavras-chave: Fermentação, exopolissacarídeos, bactérias.

\begin{abstract}
Exopolysaccharides, biopolymers or hydrosolubles gums, are produced by a great variety of microorganisms and possess physical, structural and chemical properties quite homogeneous, in relation to derived from algae and plants. The production is relatively independent on climatic conditions, faster obtaining of the finished product and need small space. Biopolymers have been studied thoroughly in the last years. Due to wide diversity in structure and physical properties, the microbial polysaccharides possess a lot of applications in food, pharmaceutical, oil, cosmetics, textile, inks and agricultural products among others industries. Some of those applications, include uses as emulsifying, stabilizing, binding, jellifying, clotting, lubricants, film coated, thickening and suspender agents. The parameters that have most influenced the process of exopolysaccharides biosyntheses have been the microorganism, the culture medium composition, $\mathrm{pH}$ and temperature of incubation. The exopolysaccharide production can be developed by species of Gram-negative and Gram-positive bacteria, some microalgae and many moulds. This work discusses the influence of these parameters during the production process and exopolysaccharides biosyntheses by bacteria.
\end{abstract}

Key words: Fermentation, exopolysaccharides, bacteria.

1 Bacharel em Química Tecnológica-Universidade Estadual de Londrina-Paraná. Aluna de Mestrado em Engenharia e Ciência de Alimentos - DETA - IBILCE - UNESP - São José do Rio Preto - São Paulo. E-mail: daniellasouza@hotmail.com

2 Professor Adjunto - Departamento de Engenharia e Tecnologia de Alimentos - IBILCE - UNESP - São José do Rio Preto - São Paulo. E-mail: crispin@ibilce.unesp.br

* Autor para correspondência.

Recebido para publicação 15/05/04 Aprovado em 25/1 1/04 


\section{Introdução}

Os polissacarídeos hidrossolúveis utilizados na industria de alimentos, também chamados de colóides hidrofílicos, hidrocolóides ou gomas são polímeros de elevado peso molecular que se dissolvem ou se dispersam em água para agir como agentes espessantes, gelificantes, estabilizantes e encapsuladores. Além disso, mostram propriedades secundárias de emulsificantes. Essas propriedades funcionais são responsáveis pela textura (corpo, viscosidade, consistência) dos alimentos processados (GLICKSMAN, 1986).

Muitos podem ser de origem vegetal, tais como: algas (alginato, ágar, carragena), sementes (gomas guar e locusta) ou exsudados de árvores (gomas arábica e karaya); outros são produtos de biossíntese microbiana (xantana, gelana, dextrana, curdlana) e, outros, são produzidos por modificações químicas de polissacarídeos naturais (pectina, gelatina, amido, carbiximetilcelulose de sódio) (GARCIA-CRUZ, 2001).

Os polissacarídeos mais estudados nos últimos anos têm sido os de origem microbiana, chamados de biopolímeros, devido a algumas vantagens de sua obtenção em relação às outras gomas, tais como: produção independente de condições climáticas, possibilidade de utilização de matérias-primas regionais, maior rapidez na obtenção do produto acabado e necessidade de espaço relativamente pequeno. Além disso, as gomas de origem microbiana apresentam maior uniformidade em suas propriedades físico-químicas devido à especificidade do microrganismo utilizado e à possibilidade de um rígido controle dos parâmetros de fermentação, como $\mathrm{pH}$, temperatura, taxa de aeração, velocidade de agitação, tempo de fermentação e composição do meio de cultura (FARIA, 2002).

Desta forma os polissacarídeos microbianos podem ser produzidos sob condições controladas e com espécies selecionadas, onde os problemas de variação de estrutura podem ser evitados. Além disso, os polissacarídeos microbianos apresentam alta regularidade estrutural, que é raramente encontrada em polímeros de outras fontes. Entretanto, há necessidade de um rígido controle das condições de fermentação, uma vez que diferentes parâmetros de produção levam à obtenção de produtos com características heterogêneas (LOPES; ANDRADE, 1995; SUTHERLAND, 2001). Além da produção, a busca por novas variedades de microrganismos que produzam polissacarídeos em grandes quantidades economicamente interessantes, é um desafio que vem sendo enfrentado por vários grupos de pesquisa em industrias, principalmente nos países desenvolvidos como Japão, EUA, Canadá e França. Embora essa área de pesquisa tenha avançado muito nos últimos tempos, é fato reconhecido que apenas poucos microrganismos foram completamente estudados dentre a vasta gama de microrganismos produtores de biopolímeros. No Brasil, também estão sendo pesquisadas novas cepas bacterianas capazes de produzirem biopolímeros extracelulares com potencial de aplicação industrial (ASHTAPUTRE; SHAH, 1995).

\section{Polissacarídeos Bacterianos}

Os exopolissacarídeos produzidos por uma grande variedade de microrganismos são gomas hidrossolúveis que possuem propriedades físicas, estruturais e químicas diferentes. Devido a essa ampla diversidade em estrutura e propriedades físicas, os polissacarídeos microbianos possuem muitas aplicações em indústrias de alimentos, farmacêutica, petrolífera, cosmética, têxtil, de tintas, produtos agrícolas entre outras. Algumas dessas aplicações, dependendo de sua estrutura química, incluem seu uso como emulsificantes, estabilizantes, ligantes, agentes gelificantes, coagulantes, lubrificantes, formadores de filmes, espessantes e agentes suspensores. Esses biopolímeros emergiram rapidamente como uma nova e importante fonte industrial de material polimérico e começaram gradualmente a competir, sob o ponto de vista econômico, com gomas naturais de algas marinhas e plantas (LOPES; ANDRADE; MANO, 1991; LOPES; ANDRADE, 1995). 
$\mathrm{Na}$ industria de alimentos a preferência por biopolímeros microbianos deve-se principalmente às suas propriedades e características funcionais, que estão relacionadas à capacidade de espessar, de manter partículas em suspensão e reter água, somadas às vantagens de uma produção independente das condições climáticas e sob condições controladas. A razão disso é a especificidade da biossíntese dos microrganismos, os quais permitem adicionalmente modificações genéticas, visando obter polissacarídeos com propriedades características específicas (SUTHERLAND, 1997).

A capacidade de produzir polissacarídeos é amplamente encontrada entre diferentes espécies microbiana, especialmente em procariontes. Um grande número de polissacarídeos bacterianos é potencialmente útil, mas relativamente poucos têm sido desenvolvidos comercialmente devido a possibilidade da bactéria ser patogênica, a produção pode ter custo elevado, a qualidade do produto pode ser dificilmente mantida e garantida ou o produto pode não alcançar aceitabilidade. Apesar desses problemas, vários polissacarídeos de bactérias Gramnegativas são economicamente viáveis e bastante utilizados, como a xantana e a gelana (SUTHERLAND, 2001).

Dos polímeros de origem bacteriana, a goma xantana tem sido a mais estudada, uma vez que seu uso em alimentos foi permitido pela "Food and Drug Administration" (FDA), desde julho de 1969 (FDA, 1969). A goma xantana comercial é produzida pela linhagem de Xanthomonas campestris utilizando xarope de glicose como fonte de carbono, derivados de amônia como fonte de nitrogênio e fatores de crescimento sob condições aeróbias a $28^{\circ} \mathrm{C}$ e agitação constante. Após a fermentação, a goma é recuperada por precipitação com etanol, seca e moída (COTTRELL; KANG; KOVACS, 1980).

A xantana é amplamente utilizada na industria de alimentos devido as propriedades de suspensão, estabilização, floculação e características pseudoplásticas de suas soluções aquosas. Pode também ser empregada na indústria farmacêutica, em pesticidas agrícolas, na fabricação de tintas e indústria têxtil devido sua alta viscosidade em pequenas concentrações, compatibilidade com sais minerais e boa estabilidade em uma ampla faixa de $\mathrm{pH}$, temperatura e força iônica (PASQUEL, 1999).

Outro polissacarídeo importante é a goma gelana, um biopolímero comercializado pela Kelco Co. (EUA) que vem sendo apontado como um dos mais eficientes e multifuncionais hidrocolóides desenvolvidos até o momento. Foi o segundo polissacarídeo de origem microbiana a ser aprovado para uso em alimentos pelo FDA, em 1992. Sua descoberta deu-se em 1977, quando a bactéria produtora Pseudomonas elodea foi identificada pela primeira vez durante uma pesquisa sobre microrganismos sintetizadores de gomas isolados do ambiente (PSZCZOLA, 1993).

A estrutura de muitos polissacarídeos de bactérias Gram-negativas é relativamente simples. São formados de homopolissacarídeos (normalmente polímeros compostos de D-glicose) ou heteropolissacarídeos, este último é normalmente composto de unidades repetidas e alinhadas desde dissacarídeos até octassacarídeos, compostos de dois a quatro tipos de monossacarídeos diferentes e muitos contêm grupos acetila e piruvato (SUTHERLAND, 2001).

As propriedades físicas de um exopolissacarídeo microbiano dependem de suas estruturas primária, secundária e terciária. Extensos estudos com polissacarídeos, por exemplo, a goma xantana produzida por bactérias selvagens e mutantes, tem fornecido alguma indicação da relação entre a estrutura do carboidrato, o grau de acilação e suas propriedades físicas (SHATWELL et al., 1990).

\section{Síntese de polissacarídeos extracelulares}

$\mathrm{Na}$ literatura há poucas informações sobre o processo da biossíntese dos diferentes tipos de exopolissacarídeos. Um bom entendimento do 
processo bioquímico é importante, pois estas informações podem ser usadas para controle e otimização da produção e também para ter conhecimento das características físico-químicas dos mesmos. Com o conhecimento do processo biossíntético podem-se adaptar os processos tecnológicos com o objetivo de diminuir os custos (DE VUYST; DEGEEST, 1999; LOOIJESTEIJN et al., 2001).

Os biopolímeros sintetizados por bactérias dividem-se em três grupos: intracelulares, integrantes da parede celular e extracelulares, segundo sua localização morfológica. A pesquisa visando aplicação industrial, de modo geral, está concentrada nos polissacarídeos extracelulares, pois apresentam um processo de extração e purificação mais simples, além de possibilitarem uma produtividade mais elevada. As bactérias Gram-negativas também têm sido apontadas como as de melhor aptidão para o processo, obviamente que para biopolímeros de uso alimentar, a bactéria não deve ser patogênica (SANDFORD, 1979; SILVA et al., 2001).

Os exopolissacarídeos possuem a função de proteger a célula bacteriana contra dessecação e ataque de fagos, bem como de antibióticos, compostos tóxicos e protozoários. Outra possível função do exopolissacarídeo inclui sequestrar cátions essenciais e envolvimento na aderência em superfícies sólidas e formação de biofilmes (DE VUYST; DEGEEST, 1999; LOOIJESTEIJN et al., 2001).

A produção de exopolissacarídeos pode ser realizada com muitas espécies de bactérias Gramnegativas e Gram-positivas, algumas algas e muitos fungos. Para isto, podem ser usados os mais diversos substratos: glicose, frutose, sacarose, lactose, amido hidrolisado, metanol, diferentes hidrocarbonetos. O custo de produção é dependente destes substratos (MARGARITIS; PACE, 1985).

Diversas pesquisas têm tentado elucidar a rota biossintética, as condições de crescimento, e a fisiologia bacteriana que leva à produção de polissacarídeos. Geralmente, a produção de exopolissacarídeo em um microrganismo é induzida pela limitação de um nutriente essencial, que não seja o carbono ou outra fonte de energia. Freqüentemente uma relação $\mathrm{C}: \mathrm{N}$ alta tem sido considerada como a condição ambiental mais significativa para a produção de polissacarídeo (NAMPOOTHIRI et al., 2003).

Alguns exopolissacarídeos são sintetizados durante todo o crescimento bacteriano enquanto que outros são produzidos somente durante a fase logarítmica ou na fase estacionária. A síntese de todos esses exopolissacarídeos é um processo intracelular utilizando açúcares difosfato nucleotídios (DE SOUZA; SUTHERLAND, 1994). Embora sejam conhecidos dois mecanismos diferentes para a síntese de exopolissacarídeos por bactérias, o utilizado na formação de dextrana, envolvendo enzimas extracelulares lipoprotéicas secretadas na superfície da célula de bactérias Gram-positivas, tal como Leuconostoc mesenteroides, não se aplica às espécies Gram-negativas. Nestas, os exopolissacarídeos (heteropolissacarídeos e homopolissacarídeos) são sintetizados intracelularmente. Os açúcares nucleotídeos (açúcar difosfato nucleotídio) fornecem as formas ativadas de monossacarídeos e também fornecem à célula bacteriana um meio de interconversão dos vários monossacarídeos através de reações de epimerização, desidrogenação e descarboxilação (HARDING et al., 1993).

Depois da polimerização das unidades repetidas o polissacarídeo é excretado através do complexo parede/membrana para a superfície celular no ambiente extracelular. Este estágio final da secreção do exopolissacarídeo na membrana citoplasmática envolve a passagem pelo periplasma, pela membrana e finalmente sua excreção para o ambiente extracelular (SUTHERLAND, 2001).

No exterior da célula microbiana os exopolissacarídeos podem permanecer soltos (como muco viscoso) ou podem estar ligados covalentemente (a um fosfodiéster ou a um lipídio) na superfície da célula. Neste último caso, o material 
pode formar uma cápsula, que pode ser reconhecida microscopicamente e que pode estar aderida firmemente à superfície (SILVA et al., 2001; WHITFIELD; ROBERTS, 1999).

Cada etapa requer uma série de enzimas e substratos específicos. A ausência de uma enzima ou substrato, em particular, inibe a síntese do exopolissacarídeo. Em Xanthomonas campestris uma série de enzimas de membrana formam a molécula aceptora do polímero (SILVA et al., 2001).

Um problema que pode ocorrer na síntese de exopolissacarídeos é a presença de polissacarases específicas ou polissacarídeo-liases que degradam o exopolissacarídeo produzido pela bactéria. Há produtos intracelulares localizados no periplasma, nos quais os genes estruturais estão estreitamente associados com aqueles para a biossíntese de polissacarídeos. Caso ocorra lise da célula durante o cultivo, as enzimas podem ser liberadas para o meio extracelular podendo ocorrer a degradação dos produtos poliméricos e a redução drástica da massa. Tais problemas são especialmente pertinentes durante a produção de alginato bacteriano e também na produção comercial de ácido hialurônico. A produção de gelana por Sphingomonas paucimobilis também envolve uma gelana-liase enquanto Xanthomonas campestris produz uma celulase (CONTI et al., 1994; SUTHERLAND; KENNEDY, 1996).

\section{Parâmetros envolvidos no processo de produção dos polissacarídeos extracelulares}

No processo de produção de polissacarídeos deve-se considerar desde o microrganismo em estudo até a determinação dos parâmetros de fermentação, onde se destaca o meio de produção e sua influência na síntese, no rendimento e na composição dos exopolissacarídeos (FARIA, 2002). Os parâmetros que mais influenciam o processo de biossíntese de exopolissacarídeos são a bactéria, a composição do meio de cultivo, o pH e a temperatura de incubação (NAMPOOTHIRI et al., 2003). Nestes têm sido pesquisadas as limitações das fontes de nitrogênio, fosfato ou enxofre em presença de excesso de carboidrato e foi observado que podem conduzir a um aumento na síntese de polissacarídeo, embora a quantidade seja também afetada pelo teor de oxigênio, $\mathrm{pH}$ e temperatura. Cada cepa bacteriana difere em sua resposta ao efeito destas mudanças ambientais e à fonte de carbono utilizada. Além disso, as condições ideais para o crescimento bacteriano e a produção de polissacarídeo em culturas descontínuas também são afetadas pela proporção entre o volume de ar e o de meio, a presença ou ausência de agitação, o tamanho do inoculo, a quantidade e a composição de micronutrientes (FARIA, 2002). Portanto, a utilização do meio de fermentação mais adequado para a produção de exopolissacarídeos irá refletir nas propriedades funcionais de cada polissacarídeo obtido (MARGARITIS; PACE, 1985).

Durante a fermentação, a fonte de carbono é convertida pela célula microbiana em biopolímero sob certos parâmetros fixos ( $\mathrm{pH}$, temperatura, tempo de incubação, etc). Geralmente, concentrações limitantes de alguns nutrientes e excesso de carboidrato favorecem a produção de polissacarídeos (SUTHERLAND, 1979). Obtém-se um alto rendimento quando ocorre a conversão de $70-80 \%$ da fonte de carbono utilizada em biopolímero (MARGARITIS; PACE, 1985).

$\mathrm{Na}$ literatura estão descritos vários meios de produção, entretanto a composição qualitativa é a mesma e cada suplemento apresenta uma determinada função na produção de polissacarídeo. Basicamente, os meios para produção de polissacarídeos apresentam uma fonte de fósforo (fosfato de potássio) e nitrogênio (sulfato de amônio) em concentrações adequadas para o crescimento do microrganismo; uma fonte de carbono (glicose, sacarose, manose, frutose e outras) como reserva energética e ainda oligoelementos como $\mathrm{Na}^{+1}, \mathrm{~K}^{+1}$, $\mathrm{Ca}^{2+}, \mathrm{Mg}^{2+}, \mathrm{Fe}^{2+}$ e outros, os quais têm um papel importante como cofatores enzimáticos nas vias de produção do polissacarídeo (MARTINS; BRITO; SÁ-CORREIA, 1990; WONG, 1993; MADI; MCNEIL; HARVEY, 1997). 
Enzimas responsáveis por alguns processos metabólicos de transferência de energia são afetadas por mudanças de $\mathrm{pH}$ e temperatura, afetando desta forma o balanço energético da célula. Por exemplo, a proporção de $\mathrm{NADH} / \mathrm{NAD}^{+}$influência a atividade da enzima lactato deidrogenase; uma alta taxa inibe esta enzima (HOFVENDAHL; VANNIEL; HAHNHÃGERDAL, 1999).

A temperatura é um fator crítico na síntese de polissacarídeos. O maior crescimento e a maior produção de polissacarídeo ocorrem na faixa de 25 $35^{\circ} \mathrm{C}$, onde cada espécie bacteriana apresenta a sua temperatura ótima (GANDHI; RAY; PATEL, 1997; KAWAI et al., 1992; VERMANI; KELKAR; KAMAT, 1995).

O oxigênio é necessário para a síntese dos monômeros do polímero ou para a oxidação e redução dos nucleotídeos. Entretanto, há pouca informação na avaliação do efeito da tensão de oxigênio dissolvido e do oxigênio utilizado para o crescimento e produção de polissacarídeo durante a fermentação (MARGARITIS; PACE, 1985).

$\mathrm{Na}$ produção de alginato por Azotobacter vinelandii o peso molecular do polímero é influenciado pela taxa de oxigênio dissolvido no meio e pela agitação do caldo de fermentação, onde alta tensão de oxigênio produz mais alginato e baixas rotações (<300 rpm) levam o microrganismo a produzir polímeros de alto peso molecular (PEÑA; TRUJILLO-ROLDÃN; GALINDO, 2000).

Em geral o tipo e a concentração da fonte de nitrogênio tem uma influência média no fluxo de carbono, na formação de produtos ou na formação de biomassa. Isto já foi relatado no caso da produção de xantana, alginato e gelana, onde uma alta proporção $\mathrm{C}: \mathrm{N}$ favorece um acúmulo de exopolissacarídeo (NAMPOOTHIRI et al., 2003).

Algumas tentativas têm sido feitas para melhorar as propriedades físicas de polissacarídeos comerciais utilizando vários meios de cultura. A otimização destas condições de cultura e do meio fermentativo têm tido êxito no caso da goma xantana (AMANULLAH et al., 1998; THORNE et al., 2000).

Nesta, foi verificado que a viscosidade pode variar em função da cepa bacteriana, do meio e condições de fermentação. A viscosidade é um parâmetro determinante para a seleção de cepas produtoras de biopolímeros. Na indústria o maior interesse é por gomas que quando adicionadas em concentrações mínimas $(0,01$ à $3 \%)$, sejam capazes de promover altas viscosidades (PASQUEL, 1999).

\section{Bactérias produtoras de exopolissacarídeos}

Os microrganismos produzem vários insumos alimentares. Estes podem ser cultivados em vários tipos de meio de cultura de baixo custo para a obtenção do metabólito desejado. Muitos microrganismos já foram isolados da natureza e utilizados industrialmente mais a maioria deles, potencialmente importantes, podem não ter sido ainda explorados, estima-se que apenas 5\% dos fungos e $2 \%$ das bactérias tenham sido devidamente identificados. Mesmo que muitas linhagens tenham sido melhoradas geneticamente em laboratório, há sempre a possibilidade de que a natureza abrigue uma linhagem com maior potencial, seja na forma selvagem, seja por melhoramento genético (SHEPHERD et al.,1995).

Um grande número de bactérias conhecidas produz quantidades abundantes de exopolissacarídeos, particularmente as patogênicas de plantas como Xanthomonas, Erwinia e bactérias fixadoras de nitrogênio Rhizobium, Beijerinkia e Azotobacter. (VERMANI; KELKAL; KAMAT, 1995). Destas, os exopolissacarídos de Xanthomonas campestris (xantana), Sphingomonas paucimobilis e Pseudomonas elodea (gelana), Acetobacter xylinum (celulose) e Rhizobium sp. (succinoglucana) estão sendo comercializados (SUTHERLAND, 2001).

A pesquisa de biopolímeros via fermentação microbiana tem uma longa história. Entre os biopolímeros mais estudados estão os alginatos 
bacterianos produzidos por Pseudomonas sp., dextrana de Leuconostoc mesenteroides, xantana por Xanthomonas campestris, pequenas quantidades de cellulose de Acetobacter xylinium, ácido hialurônico de Streptococcus equii, succinoglucana de Rhizobium e gelana de Sphingomonas paucimobilis e Pseudomonas elodea (NAMPOOTHIRI et al., 2003).

Muitas bactérias Gram-negativas podem produzir mais de um exopolissacarídeo: Xanthomonas campestris produz somente um único exopolissacarídeo, a xantana. Rhizobium e outras espécies de bactérias podem sintetizar dois ou mesmo três polímeros extracelulares, juntamente com oligossacarídeos intracelulares, contudo a síntese dessas moléculas pode não ser expressada simultaneamente (TANG et al., 1991).

Algumas bactérias ácido láticas como Lactococcus lactis produzem polissacarídeos extracelulares que são economicamente interessantes porque podem conferir efeitos funcionais nos alimentos e benefícios a saúde. A maioria dos estudos de produção de exopolissacarídeos por bactérias ácido láticas focaliza a influência das condições de desenvolvimento fisiológico na biossíntese de exopolissacarídeos, na genética da biossíntese e na elucidação da composição da estrutura primária destes exopolissacarídeos (LOOIJESTEIJN et al., 2001; WELMAN; MADDOX, 2003).

\section{Composição dos Biopolímeros bacterianos e suas aplicações}

A composição dos biopolímeros é limitada a um número pequeno de monossacarídeos e outros componentes não carboidratos, principalmente, os grupamentos acetila e piruvato que são responsáveis pela viscosidade das soluções aquosas destes polímeros. Porém, as soluções aquosas destes polímeros apresentam diversidade nas propriedades físicas. Alguns destes polímeros produzem soluções altamente viscosas, e outros podem formar géis semelhantes ao ágar, pela adição de sais (SOUW; DEMAIN, 1979; CRESCENZI, 1995).

A goma xantana, produzida por Xanthomonas campestris, por exemplo é composta de glicose, manose, ácido glucurônico, ácido pirúvico e grupos acetila. A goma gelana obtida de Pseudomonas elodea possui em sua composição glicose, ramnose, ácido urônico e grupos acetila (SANDFORD, 1979; KANG; VEEDER; COTTRELL, 1983).

Os grupos acetila e outros substituintes nãoaçúcares podem alterar grandemente as propriedades físicas, assim como conferir carga ao exopolissacarídeo. $\mathrm{Na}$ ausência de tais cargas as macromoléculas podem ser insolúveis, contudo, dependem das ligações estruturais. $\mathrm{O}$ piruvato e o acetato influenciam a transição e estabilização ou desestabilização da conformação ordenada, respectivamente. Grupos acetila geralmente impedem a associação sinergística e sua remoção produz polímeros gelificantes em concentrações baixas (SUTHERLAND, 1997).

Os polissacarídeos microbianos produzidos comercialmente têm sido aceitos por vários motivos: alguns são biologicamente similares aos polímeros de eucariotos, como por exemplo o ácido hialurônico, outros são excelentes agentes gelificantes ou suspensores com alta estabilidade em um amplo intervalo de $\mathrm{pH}$ e temperatura. Por exemplo a goma xantana é um excelente agente suspensor, enquanto que a goma gelana produz géis muitos resistentes e puros, os quais têm encontrado uma série de aplicações em biotecnologia. Outros polissacarídeos, incluindo o homopolímero $\beta$ - D-glucana, possuem atividade biológica como estimulante imunológico ou agente supressor de tumores. Entretanto, somente a goma xantana e a gelana têm aprovação para uso em alimentos na Europa e América. Outros polissacarídeos produzidos por bactérias Gramnegativas não têm aprovação como aditivo alimentar, embora alguns como Acetobacter xylinum estejam envolvidos em fermentações tradicionais (SHEPHERD et al., 1995; SUTHERLAND, 2001). 
Dos vários polissacarídeos comercializados somente um número limitado está liberado em produtos industriais. A xantana é produzida em larga escala e é utilizada em vários produtos alimentícios. A celulose bacteriana é um produto com um grande número de aplicações especializadas. A curdlana é usada no Japão como um aditivo alimentar, mais não é permitida na América do Norte e Europa. A gelana é usada em alimentos, além de outras aplicações como agente gelificante (SUTHERLAND, 2001).

A dextrana é um homopolissacarídeo extracelular ramificado, sintetizado por Leuconostoc mesenteroides e constiuída por unidades de D-glicose unidas por ligações $\alpha(1-6)$. A dextrana foi o primeiro polissacarídeo microbiano produzido em escala industrial (LOPES; ANDRADE, 1995).

Exopolissacarídeos de bactérias ácido láticas tem apresentado aplicações no aprimoramento da reologia, textura e corpo de produtos láticos fermentados, tal como iogurte. Estes exopolissacarídeos apresentam cadeias longas e ramificadas, com unidades repetidas de monossacarídeos, principalmente glicose, manose, galactose, ácido glucurônico e, as vezes, ramnose em diferentes proporções ou derivados destes açúcares (McKELLAR; GEEST; CUI, 2003; WELMAN; MADDOX, 2003).

A curdlana sintetizada por Agrobacterium radiobacter, é formada exclusivamnete por unidades de $\beta$ - D-glicose, com ligações glicosídicas $\beta(1-3)$. Vários estudos indicam que a curdlana não possui valor calórico, aplicando-se assim a alimentos de baixa caloria. Succinoglicana sintetizada por Agrobacterium radiobacter são compostas de $80 \%$ glicose, $10 \%$ galactose, $5 \%$ ácido pirúvico e algumas unidades de ácidos succínico e acético (LOPES; ANDRADE, 1995; McKELLAR; GEEST; CUI, 2003).

\section{Referências}

AMANULLAH, A.; SERRANO-CARREON, L.; CASTRO, B.; GALINDO, E.; NIENOW, A. W. The influence of impeller type in pilot scale xanthan fermentation. Biotechnology Bioengineering, New York, v.57, p.95-108, 1998.
ASHTAPUTRE, A. A.; SHAH, A. K. Studies on a viscous, gel-forming exopolysaccharide from Sphingomonas paucimobilis GS1. Applied and Environmental Microbiology, Washington, v.61, n.3, p.1159-1162, 1995.

CONTI, E.; FLAIBANI, A.; REGAN, M.; SUTHERLAND, I. W. Alginate from Pseudomonas fluorescens and Pseudomonas putida: production and properties. Microbiology, New York, v.140, p.1128-1132, 1994.

COTTRELL, I. W.; KANG, K. S.; KOVACS, P. Handbook of water-soluble gums and resins. New York: Mc Graw Hill, 1980.

CRESCENZI, V. Microbial polysaccharides of applied interest: ongoing research activities in Europe. Biotechnology Progress, New York, v.11, p.251-259, 1995.

DE SOUZA, A. M.; SUTHERLAND, I. W. Exopolysaccharide and storage polymer production in Enterobacter aerogenes type 8 strains. Journal of Applied Bacteriology, Oxford, v.76, p.463-468, 1994.

DE VUYST, L.; DEGEEST, B. Heteropolysaccharides from lactic acid bacteria. FEMS Microbiology, Amsterdam, v.23, n.2, p.153-177, 1999.

FARIA, L. H. G. B. Caracterização taxonômica e produção de polissacarídeos utilizando bactérias isoladas de amostras de solo. 2002. Tese (Mestrado em Engenharia e Ciência de Alimentos) - Instituto de Biociências, Letras e Ciências Exatas, Universidade Estadual Paulista, São José do Rio Preto, 2002.

FOOD \& DRUG ADMINISTRATION. Food additives permitted in food for human consumption: xanthan gum. Federal Register, Washington, v.34, n.53, part 121, p.5376, mar. 1969.

GANDHI, H. P.; RAY, R. M.; PATEL, R. M. Exopolymer production by Bacillus species. Carbohydrate Polymers, Barking, v.34, p.323-327, 1997.

GARCIA-CRUZ, C. H. Uso de hidrocolóides em alimentos: revisão. Higiene Alimentar, São Paulo, v.15, n.87, p.19-29, 2001.

GLICKSMAN, M. Hydrocolloid functionality in fabricated foods. Food Technology, Chicago, v.38, n.1, p.17-21, 1986.

HARDING, N. E.; RAFFO, S.; RAIMONDI, A.; CLEARY, J. M.; IELPI, L. Identification, genetic and biochemical analysis of genes involved in synthesis of sugar nucleotide precursors of xanthan gum. Journal of General Microbiology, London, v.139, p.447-457, 1993.

HOFVENDAHL, K.; VANNIEL, E. W.; HAHNHÃGERDAL, B. Effect of temperature and $\mathrm{pH}$ on growth and product formation of Lactococcus lactis ssp. Lactis ATCC 19435 growing on maltose. Applied Microbiology and Biottechnology, Washington, v.51, p.669-672, 1999. 
KANG, K. S.; VEEDER, G. T.; COTTRELL, I. W. Some novel bacterial polysaccharides of recent development. In: BUSHELL, M. E. (Ed.). Progress in industrial microbiology: modern applications of traditional biotechnologies. New York: Elsevier, 1983. v.18, p.231-257.

KAWAI, H.; ISOBE, Y.; KORIBE, M.; TOKUDA, J.; TOKUNO, I.; ENDO, K.; KAWAI, F. Production of a novel extracellular polysaccharide by a Bacillus strain isolated from Soil. Bioscience Biotechnology and Biochemistry, Tokio, v.56, n.6, p.853-857, 1992.

LOOIJESTEIJN, J. P.; TRAPET, L.; VRIES, E.; ABEE, T.; HUGENHOLTZ, J. Physiological function of exopolysaccharides produces by Lactococcus lactis. International Journal of Food Microbiology, Amsterdam, v.64, p.71-80, 2001.

LOPES, L.; ANDRADE, C. T. Polímeros de origem microbiana: polissacarídeos bacterianos. Revista de Química Industrial, Rio de janeiro, v.703, p.19-23, out./ dez 1995.

LOPES, L.; ANDRADE, C. T.; MANO, E. B. O valor das gomas para as industrias. Ciência Hoje, São Paulo, v.12, n.71, p.65-67, mar.1991.

MADI, N. B.; MCNEIL, B.; HARVEY, M. Effect of exogenous calcium on morphological development and biopolymer synthesis in the fungus Aureobasidium pullulans. Enzyme and Microbial Technology, New York, v.21, p.102-107, 1997.

MARGARITIS, A.; PACE, G. W. Microbial polysaccharides. In: Comprehensive Biotechnology. Canada: University of Waterloo, 1985. cap.49, p.1005-1044.

MARTINS, L. O.; BRITO, L. C.; SÁ-CORREIA, I. Roles of $\mathrm{Mn}^{2+}, \mathrm{Mg}^{2+}$ and $\mathrm{Ca}^{2+}$ on alginate biosynthesis by Pseudomonas aeruginosa. Enzyme and Microbial Technology, New York, v.12, p.794-799, 1990.

McKELLAR, R. C.; GEEST, J. V.; CUI, W. In fluence of culture and environmental conditions on the composition of exopolysaccharide produced by Agrobacterium radiobacter. Food hydrocolloids, Oxford, v.17, p.429-437, 2003.

NAMPOOTHIRI, K. M.; SINGHANIA, R. R.; SABARINATH, C.; PANDEY, A. Fermentative production of gellan using Sphingomonas paucimobilis. Process Biochemistry, London, v.38, p.1513-1519, 2003.

PASQUEL, A. Gomas: Utilização e aspectos reológicos. Boletim da Sociedade Brasileira de Ciencia e Tecnologia de Alimentos, Campinas, v.33, n.1, p.86-87, 1999.

PEÑA, C.; TRUJILLO-ROLDÃN, M. A.;GALINDO, H. Influence of dissolved oxygen tension and agitation speed on alginate production and its molecular weight in cultures of Azotobacter vinelandii. Enzyme and Microbial Technology, New York, v.27, p.390-398, 2000.

PSZCZOLA, D. E. Gellan gum wins IFT's Food Technology Industrial Achievement award. Food Technology, Chicago, v.47, n.9, p.94-96, 1993.

SANDFORD, P. A. Exocellular microbial polysaccharides. Advance in Carbohydrate Chemistry and Biochemistry, New York, v.36, p.265-313, 1979.

SHATWELL, K. P.; SUTHERLAND, I. W.; DEA, I. C. M.; ROSS- MURPHY, S. B. The influence of acetyl and piruvate substituents on the helix-coil transition behavior of xanthan. Carbohydrate Research, Amsterdam, v.206, p.87-103, 1990.

SHEPHERD, R.; ROCKEY, J.; SUTHERLAND, I. W.; ROLLER, S. Novel bioemulsifiers from microorganisms for use in foods. Journal of Biotechnology, Amsterdam, v.40, p.207-217, 1995.

SILVA, F. R.; VETTORE, A. L.; KEMPER, E. L.; LEITE, A.; ARRUDA, P. Fastidiam gum: the Xylella fastidiosa exopolysaccharide possibly involved in bacterial pathogenicity. FEMS Microbiology Letters, Amsterdam, n.203, p.165-171, 2001.

SOUW, P.; DEMAIN, A. L., Nutritional studies on xanthan production by Xanthomonas campestris NRRL-B-1459. Applied Environmental Microbiology, Washington, v.37, n.6, p.1186, 1979.

SUTHERLAND, I. W. Bacterial exopolysaccharides. Advances in Microbial Physiology, London, v.8, p.142213, 1979.

SUTHERLAND, I. W.; KENNEDY, L. Polysaccharide lyases from gellan-producing Sphingomonas spp. Microbiology, New York, n.142, p.867-872, 1996.

SUTHERLAND, I. W. Microbial exopolysaccharides: structural subtleties and their consequences. Pure \& Applied Chemistry, Oxford, v.69, n.9, p.1911-1917, 1997.

SUTHERLAND, I. W. Microbial polysaccharides from gram-negative. International Dairy Journal, Barking, n.11,p.663-674, 2001.

TANG, J. L.; LIU, Y. N.; BARBER, C. E.; DOW, J. M.; WOOTTON, J. C.; DANIELS, M. J. Genetic and molecular analysis of a cluster of $r p f$ genes involved in positive regulation of synthesis of extracellular enzymes and polysaccharide in Xanthomonas campestris pathovar campestris. Molecular and General Genetics, New York, v.226, p.409-417, 1991.

THORNE, L.; MIKOLAJCZAK, M. J.; ARMENTROUT, R. W.; POLLOCK, T. J. Increasing the yield and viscosity of exopolysaccharide secreted by Sphingomonas by 
augmentation of chromosomal genes with multiple copies of cloned biosynthetic genes. Journal of Industrial Microbiology and Biotechnology, Hampshire, n.25, p.4957, 2000 .

VERMANI, M. V.; KELKAR, S. M.; KAMAT, M Y. Production and optimization of certain growth parameters for an exopolysaccharide from Azotobacter vinelandii MTCC 2460 isolated from a plant rhizosphere. Journal of Fermentation and Bioengineering, Osaka, v.80, n.6, p.599602, 1995.
WELMAN, A. D.; MADDOX, I. S. Exopolysaccharides from lactic acid bacteria: perspectives and challenges. Trends in Biotechnology, Amsterdam, v.21, n.6, p.269-274, 2003.

WHITFIELD, C.; ROBERTS, I. S. Structure, assembly and regulation of expression of capsules in Escherichia coli. Molecular Microbiology, Salem, n.31, p.1307-1319, 1999.

WONG,T, Y. Effects of calcium on sugar transport in Azotobacter vinelandii. Applied and Environmental Microbiology, Washington, v.59, n.1, p.89-92, 1993. 